\title{
Nonlinear Dynamics of Heavy Structures
}

\author{
Yury Izvekov ${ }^{1, *}$, Oleg Tulupov ${ }^{1}$, Irina Kinzina $^{1}$, and Alexey Kanel-Belov ${ }^{2}$ \\ ${ }^{1}$ Department of Applied Mathematics and Informatics, Nosov Magnitogorsk State Technical \\ University, Magnitogorsk, Russia \\ ${ }^{2}$ Department of Mathematics, Bar-Ilan University, Ramat Gan, Israel
}

\begin{abstract}
At the moment, not enough attention is paid to different aspects of nonlinear dynamics for heavy structures. In this article we attempt to create a mathematical model for finding a frame (field) with predictable dynamic pattern of load-carrying capability for a heavy structure based on the parameters of its reliable (failure-free, low-risk) operation. It is difficult to find a solution for this problem now but the following algorithm can be applied. Small dimension projection is first obtained for orthonormal vectors determining the structural load-carrying capability. Then we use available methods to find a field where any relationship (functional, logical) can be obtained between the rules (wild cards) and the loadcarrying capability displayed by a heavy structure. This article carries on the cycle of activities on structural risk analysis involving heavy structures. Numerical and calculated data are based on previous studies. The analysis is performed on a metallurgical overhead crane. The obtained findings are used for adopting various engineering solutions at different stages of heavy structure operation.
\end{abstract}

\section{Introduction}

Applicability of risk analysis for heavy structures was demonstrated by the authors in their previous studies $[1,2]$. As representatives of one of the science departments of the Nosov Magnitogorsk State Technical University, the authors conventionally utilize the resources provided by vector-matrix algebra and structural matrix mechanisms when addressing various process- and equipment-related problems in rolling production [3, 4]. Due to the increased industrial safety requirements, the performance of risk analysis for heavy technological and auxiliary equipment based on the above-mentioned experience, together with quantitative and qualitative evaluation of performance that is critical from the perspective of technology and safe operation of facilities, are particularly important in steelmaking industry. The heavy structure representing the target of research in this article is a metallurgical overhead crane. This structure comprises four critical subsystems: the steel structure of the bridge itself including main and auxiliary bridge girders; longitudinal beams of the auxiliary bridge; crossbeam of the main hoist mechanism including hooks and steel structure of the crossbeam; ratchet gear of the main hoist mechanism [2]. All of these

\footnotetext{
*Corresponding author: yurij.izvekov@mail.ru
} 
elements have the same impact on structural reliability and we can introduce the following normalization requirement by defining the structural elements as $a_{i}$ :

$$
\sum_{i=1}^{4} a_{i}=1 .
$$

In our opinion, the nonlinear dynamics displayed by these structures is worth particular interest [5-7].

\section{Research Materials and Methods, Discussion}

Load carrying capability $\mathrm{S}$ of the structure can be defined as the point coordinates within four-dimensional space whereas its growth or decrease will be defined as its present condition. This space will always contain fields associated with high risk for the structure. We shall refer to such field as wild cards (rules) [6,7], according to which the structure can transit to a certain point within the frame $[6,7]$ or to another wild card, with a certain degree of probability $\mathrm{P}(\mathrm{t})$. In this case, a wild card can drastically change its bifurcation diagram and (or) prevent the resulting chaos. We must find a field with predictable dynamic pattern of structural load-carrying capability S. This problem appears to be challenging but the following ideas seem to be interesting.

We believe that the structural load-carrying capability $\mathrm{S}$ is determined by multiple variables including the fatigue of the load-bearing structure, various defects (including accumulated defects), the number of cycles exceeding the permissible standards, the effective stresses and strains and many other factors.

Let us find the small dimension projection for orthonormal vectors determining the dynamics of load-carrying capability $\mathrm{S}$ displayed by the examined structure. Then we can clearly write down the following equation:

$$
S(t)=F(\vec{N}, \vec{\sigma}, \vec{\varepsilon})
$$

$\vec{N}$ is the cycle vector attained by the structure during its operation;

$\vec{\sigma}, \vec{\varepsilon}$ are the effective stress and strain vectors.

Based on [1-13] and operational documentation we can assume that the above three vectors are the main ones, which determine the dynamics of the structural load-carrying capability, reliability $\mathrm{P}$ and risk of integral failure $\mathrm{R}$ for the entire structure.

It was demonstrated in the previous studies $[1,2]$ that the function of probability density for the number of cycles and the effective stresses and strains of structures operating in heavy-loaded conditions is subject to the normal law of distribution. Thus, the expected value $\bar{S}$, the dispersion $S^{2}$ and the function of probability density for the load-carrying capability can be represented as follows:

$$
\begin{array}{r}
f(S)=\frac{1}{\sqrt{2 \pi S^{2}}} e^{-\frac{(S-\bar{S})^{2}}{2 S^{2}},} \\
\bar{S}=\int S f(S) d S, \\
S^{2}=\int S^{2} f(S) d S-\bar{S}^{2} .
\end{array}
$$


Based on [3-5], we assume that the structural load-carrying capability will conform to the following rules (wild cards):

$G_{1}$ refers to normal load-carrying capability of the structure (reliability of all the elements is greater than or equal to 0.841 [2]);

$G_{2}$ refers to maximum permissible load-carrying capability of the structure (reliability of all the elements is greater than or equal to 0.479 [2]);

$G_{3}$ refers to catastrophic load-carrying capability of the structure (reliability of all the elements is less than or equal to 0.250 [2]).

Hence, we can write that the structural load-carrying capability can conform to the above rules as follows:

$$
S=F\left(\vec{G}_{1} ; \vec{G}_{2} ; \vec{G}_{3}\right) .
$$

Wild cards can be represented as vectors.

At the moment, the analysis of frames and wild cards is only presented using the terms applied in logical algebra [6,7]. The proposed approach appears to be quite promising and expands the possibilities of nonlinear dynamics for each particular situation and structure.

Using the available numerical and calculated data on the number of cycles, stresses and strains [2], together with the proposed research method, we can represent the dynamic pattern of load-carrying capability displayed by the metallurgical crane structure comprising four basic subsystems.

Matrix of structural load-carrying capability can be represented as tables 1-3 below:

Table 1. Load-carrying capability at the start of operation

\begin{tabular}{|c|c|c|}
\hline $\mathrm{G} 1$ & $\mathrm{G} 2$ & $\mathrm{G} 3$ \\
\hline 0.8410 & 0.1090 & 0.0500 \\
\hline 0.3710 & 0.4790 & 0.1500 \\
\hline 0.2500 & 0.5000 & 0.2500 \\
\hline
\end{tabular}

Table 2. Load-carrying capability after 15 years of operation

\begin{tabular}{|c|c|c|}
\hline $\mathrm{G} 1$ & $\mathrm{G} 2$ & $\mathrm{G} 3$ \\
\hline 0.4257 & 0.4855 & 0.0889 \\
\hline 0.4568 & 0.3539 & 0.1894 \\
\hline 0.4425 & 0.3200 & 0.2375 \\
\hline
\end{tabular}

Table 3. Load-carrying capability after 25 years of operation

\begin{tabular}{|c|c|c|}
\hline $\mathrm{G} 1$ & $\mathrm{G} 2$ & $\mathrm{G} 3$ \\
\hline 0.3157 & 0.2959 & 0.3883 \\
\hline 0.3154 & 0.2935 & 0.3911 \\
\hline 0.3156 & 0.2946 & 0.3898 \\
\hline
\end{tabular}

The probability of reliable (failure-free) operation of the structure is shown in the matrix. This allowed to obtain the following diagram (figure 1). 


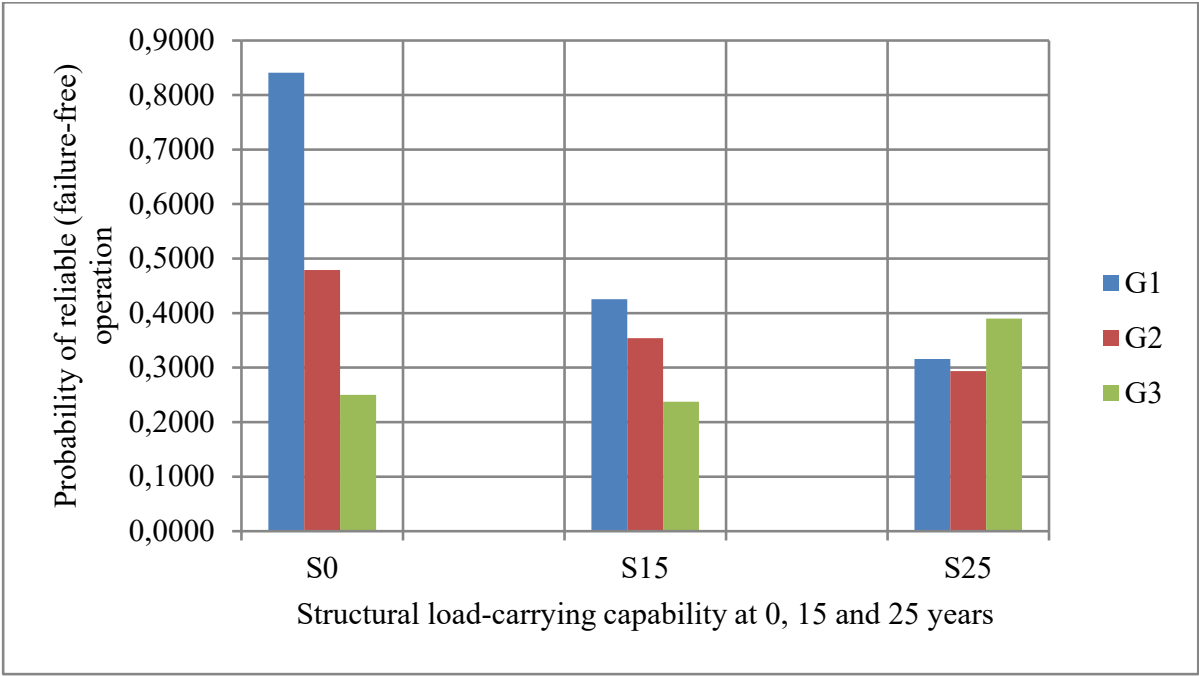

Fig. 1. Structural load-carrying capability

The presented diagram allows to trace the dynamics of structural load-carrying capability and to see that after 25 years of operation under heavy and extra-heavy conditions the G3 wild card (rule) will be observed more and more. Considering that the average operating life of metallurgical overhead cranes is 25-30 years, the proposed approach can describe the real situation quite adequately.

Therefore, the load-carrying capability of a heavy structure can be controlled by establishing the level of maintenance or continuous remote monitoring.

\section{Conclusions}

Nonlinear dynamics of such heavy and complex structures as metallurgical overhead cranes represents an immediate and significant issue. Analyzing real objects represents a very interesting task.

Even though the problem is really difficult to solve, the following can be applied: identifying vectors that determine the structural load-bearing capability and finding functional and logical relationship between these vectors and the structural load-bearing capability.

The above relationships can be used to monitor such complex structures on a continuous basis, which constitutes unconditional basis for their successful operation and can represent the basis for creating the so-called "digital twins" of such equipment.

\section{References}

1. Yu. A. Izvekov, O.A. Torshina, A.A. Anisimov, G.E. Kameneva, T.A. Bondarenko, Probabilistic modeling of crack growth in large structures, ICMTMTE 2020 MATEC Web of Conferences 329, $03021 \quad$ (2020), https://doi.org/10.1051/matecconf/202032903021

2. Yu.A. Izvekov, V.V. Dubrovsky, A.L. Anisimov, Dynamic pattern of safe operation indicators for heavy machines, International conference on industrial machine building, Springer, Cham, pp. 595-601 (2020) 
3. O.N.Tulupov, A.B. Moller, D.I.Kinzin, S.A. Levandovskiy, N.A. Ruchinskaya, A.V. Nalivaiko, S.S. Rychkov, E.N. Ishmetyev, Structural-matrix model for long product rolling processes; modeling production traceability and forming consumer properties of products, Vestnik of Nosov Magnitogorsk State Technical University, 5, 46 (2013)

4. O.N. Tulupov, Rashnikov S.F, Matrix mathematical modeling of roll pass design. Modeling of Metal Rolling Processes 3, Conference Papers, The Chameleon Press Limited, London, pp. 458-467 (1999)

5. K.V. Frolov, N.A. Makhutov, Bezopasnost Rossii. Pravovye, sotsialnoekonomicheskie $i$ nauchno-tekhnicheskie aspekty (Safety of Russia. Legal, Socioeconomic, and Scientific and Technical aspects), In 4 Parts, Part 1: The Basic Concepts of the Analysis and Regulation of Safety, Znanie, Moscow (2006)

6. G.G. Malinetsky, A.B. Potapov, Sovremenniye problemy nelineynoy dinamiki (Current issues involved with nonlinear dynamics), Editoral URSS, Moscow (2000)

7. G.G. Malinetsky, Upravleniye riskom i redkiye catastrophicheskiye sobytiya (Risk management and occasional catastrophic events), Mathematical simulation, 14:8, pp. $107-112$ (2002)

8. SP 16.13330 2011. Steel structures. Updated version of SNiP II-23-81

9. SP 20.13330 2011. Loads and actions. Updated version of SNiP 2.01.07-85

10. GOST 28609-90, Cranes. Basic provisions of design (1992)

11. G. Taguchi, Quality Engineering in Japan, Bull. Japan Soc. Precis. Eng. 4, pp. 237242 (1985)

12. D.B. Hammad, N. Shafiq, M.F. Nuruddin, Criticality Index of Building Systems Using Multi-Criteria Decision Analysis Technique, MATEC Web of Conferences, EDP Sciences 15:01018 (2014)

13. H. Kumamoto, E.J. Henley, Probabilistic Risk Assessment and Management for Engineers and Scientists, IEEE Press, New York (1996) 